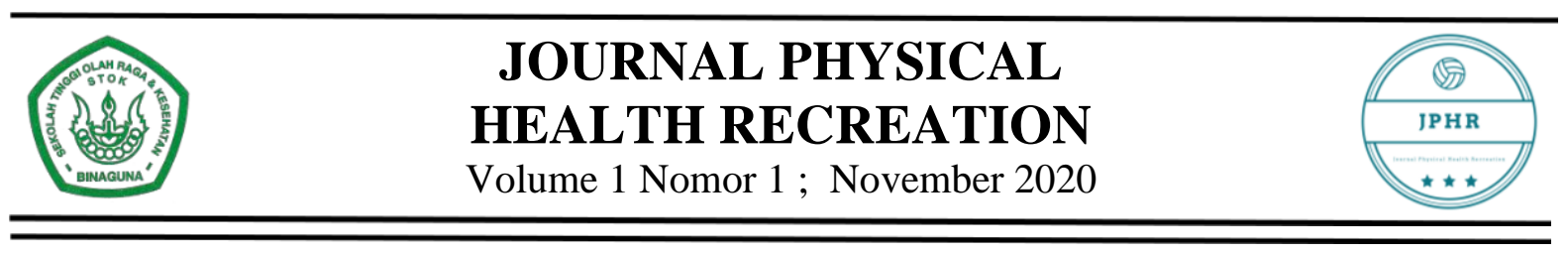

\title{
IMPROVEMENT OF LEARNING PASSING BASKETBALL LEARNING THROUGH APPLICATION OF VARIATION (Action Research Study Business Management Students of SMK Sinar Husni Helvetia)
}

\author{
PENINGKATAN HASIL BELAJAR DRIBBLE BOLA BASKET MELALUI \\ PENERAPAN VARIASI PEMBELAJARAN \\ (Studi Penelitian Tindakan Pada Siswa SMK Bisnis Manajemen Sinar Husni \\ Helvetia)
}

\section{SYAFRIZAL}

SMKS SINAR HUSNI 2 TR

Jl. Veteran Gg. Utama Pasar V Helvetia

Email: syafrizalrizal500@gmail.com

\begin{abstract}
ABSTRAK
Penelitian action research ini bertujuan untuk meningkatkan hasil belajar passing bola basket melalui penerapan variasi pembelajaran pendidikan jasmani. Selain itu, penelitian ini dilakukan untuk memperoleh informasi tentang penerapan variasi pembelajaran untuk siswa Sekolah Menengah Kejuruan dan juga mengetahui efektifitas, efesiensi dan juga peningkatan hasil belajar tentang pelaksanaan passing (mengoper) bola basket bagi siswa kelas X Sekolah Menengah Kejuruan. Subjek dalam penelitian ini berjumlah 36 orang siswa yang merupakan siswa kelas X SMK Bisnis Manajemen Sinar Husni Helvetia. Untuk menguji keefektitasan variasi pembelajaran ini dapat dilihat dari data psikomotorik dan tes hasil menggiring bola peda permainan bola basket. Pada hasil tes pembelajaran awal (pre test) diperoleh hasil 30,56\% dari kriteria yang diharapkan. Sedangkan setelah dilakukan pembelajaran siklus I dengan variasi pembelajaran terjadi peningkatan keefektifitasan sebesar 58,33\% dari kriteria yang diharapkan. Kemudian dilanjutkan pada pembelajaran siklus II melalui penerapan variasi pembelajaran diperoleh $89,89 \%$ dari kriteria yang diharapkan, yang berarti mengalami peningkatan sebesar 59,33\% Berdasarkan hasil penelitian ini dapat disimpulkan bahwa : (1) dengan penerapan variasi pembelajaran siswa menjadi lebih aktif, dan termotivasi dalam belajar pendidikan jasmani terutama pada pembelajaran bola basket, (2) dengan variasi pembelajaran dapat meningkatkan hasil belajar mengoper bola pada permainan bola basket siswa.
\end{abstract}

Kata Kunci : Variasi Pembelajaran, Passing Bola Basket

\section{ABSTRACT}

This action research study aims to improve learning outcomes passsing the basketball through the application of physical education learning variations. In addition, this study was conducted to obtain information about the application of learning variations for Vocational 
High School students and also find out the effectiveness, efficiency and improved learning outcomes on the implementation of the passing (pass) basketball for class X Vocational Education. Subjects in this study amounted to 36 students who are students of class X SMK Sinar Husni Business Management Helvetia. To test keefektitasan learning variation can be seen from the data and the psychomotor test results peda dribble a basketball game. At the beginning of learning the test results (pre-test) results obtained $30.56 \%$ of the expected criteria. Meanwhile, after learning the first cycle with an increase in the effectiveness of learning variation of $58.33 \%$ of the expected criteria. Then proceed to the second cycle of learning through the application of learning variations obtained $89.89 \%$ of the expected criteria, which represented an increase of $59.33 \%$ Based on these results it can be concluded that: (1) the application of the variation of student learning becomes more active, and motivated in learning physical education, especially in learning basketball, (2) with a variety of learning can improve learning outcomes passing the basketball game students.

\section{Keywords: Variation Application of Learning, Passing Basketball}

\section{PENDAHULUAN}

Sekolah merupakan sebuah lembaga pendidikan yang mempunyai tugas utama untuk menghantarkan peserta didik agar mampu mengenal dan mengembangkan setiap potensi yang ada di dalam dirinya. Sekolah juga dikenal sebagai sebuah wadah untuk mengembangkan kepribadian seorang manusia agar memperoleh sebuah hidup yang lebih baik dimasa yang akan datang. Dengan berjalan efektif proses pembelajaran di dalam maupun di luar kelas maka akan menciptakan sebuah kondisi yang memudahkan seluruh elemen yang terlibat, baik guru maupun siswa untuk menjalankan aktivitas kependidikan.

SMK Bisnis Manajemen Sinar Husni merupakan salah satu Sekolah Menengah Kejuruan yang besar yang terdapat di daerah Deli Serdang yang bergerak pada bidang ilmu Bisnis Menejemen. Sekolah ini memiliki pelengkapan sarana dan prasarana yang memadai untuk proses pembelajaran khususnya pembelajaran pendidikan jasmani. Dari observasi dan pencarian informasi yang dilakukan peneliti diketahui bahwa siswi SMK Bisnis Manajemen Sinar Husni, pada saat proses pembelajaran pendidikan jasmani dalam materi permainan bola basket khususnya pada materi passing bola basket, dimana masih banyak para siswa yang belum memahami teknik dasar permainan bola basket khususnya dalam passing (mengoper) bola basket.
Partisipasi dan peran aktif para siswi dalam proses pembelajaran pendidikan jasmani dapat dikatakan cukup rendah, hal ini terjadi karena guru pendidikan jasmani kurang mampu menyajikan proses pembelajaran yang menyenangkan bagi para siswasiswinya. Selain itu ketidak mampuan sebahagian besar siswa dalam melakukan passing bola basket dengan benar lebih dikarenakan pada siswa tersebut bukan mendorong bola kearah depan dengan ujung jari dan telapak tangan melainkan melemparkan bola dengan kedua tangan yang menjadikan gerakan passing bola tidak sempurna. Selain itu pembelajaran yang monoton karena kurang mampu mengembangkan berbagai variasi pembelajaran yang beragam membuat para siswa sulit megembangkan kemempuan passing bola basketnya.

Benny Aprial. M dan Dicky Hendrawan dalam jurnal 1st Unimed International Conference on Sport Science (UnICoSS 2019) Physical education materials consist of small ball games, big ball games, athletics, gymnastics, water activities, and health lifestyle. Each student must meet the material competency qualifications with the teaching process delivered by the Physical Education teacher. The material contained in Physical Education is generally the same in each education unit, but the difference is the studies and insights that are adjusted to the level of the education unit.

Dalam hal ini salah satu alternatif yang dilakukan 
untuk mengatasi masalah ini adalah dengan mencoba metode penerapan variasi mengajar dalam pembelajaran passing bola basket. Diharapkan dengan memasukkan berbagai bentuk variasi belajar pada proses pembelajaran pendidikan jasmani khususnya pada pembelajaran bola basket dapat meningkatkan kembali keaktifan para peserta didik dalam mengikuti proses pembelajaran, serta memperbaiki hasil belajar pendidikan jasmani khususnya pada pembelajaran passing bola basket.

Berdasarkan uraian latar belakang diatas, maka peneliti mengangkat sebuah fokus permasalahan mengenai "Peningkatan Hasil Belajar Passing Bola Basket Melalui Penerapan Variasi Pembelajaran (Sebuah Studi Penelitian Tindakan Terhadap Siswa SMK BM Sinar Husni Helvetia”

\section{METODE PENELITIAN}

Tujuan penelitian variasi pembelajaran dribble bola basket yakni :

1. Untuk memperoleh informasi secara mendalam tentang proses pelaksanaan pembelajaran dribble atau menggiring bola basket pada siswa Sekolah Menengah Kejuruan (SMK)

2. Mengembangkan dan menerapkan proses pembelajaran melalui penerapan metode variasi pembelajaran dengan alat yang sederhana, menarik, efektif dan juga efisien

3. Memperoleh data empiris tentang efektivitas, efesiensi, dan daya tarik siswa dalam meningkatkan kemampuan hasil belajar dribble bola basket melalui peneran metode variasi pembelajaran siswa Ssekolah Menengah Kejuruan (SMK)

4. Tujuan akhir dari penelitian ini adalah meningkatkan kemampuan dribble atau menggiring bola basket pada siswa sekolah menengah kejuruan melalui metode penerapan variasi pembelajaran dengan alat sederhana yang efektif dan juga efisien.

Penelitian ini dilaksanakan di SMK Bisnis Manajemen Sinar Husni Helvetia Deli Serdang. Penelitian ini dilaksanakan pada bulan Agustus 2020 sampai dengan selesai, dimana dalam aplikasi setiap pelaksanaan siklus berpedoman pada RPP sekolah tersebut. Dengan subjek penelitian ini adalah siswa kelas $\mathrm{X}$ SMK Bisnis Manajemen Sinar Husni Helvetia Deli Serdang, yang diperoleh berdasarkan metode dari Random Sampling.

Metode penelitian yang digunakan pada penelitian ini adalah metode Penelitian Tindakan (action research) dengan desain Kemmis dan Taggart yang membagi prosedur penelitian ini dalam empat tahapan kegiatan pada satu putaran siklus, yaitu perencanaan, pelaksanaan tindakan, observasi dan refleksi.

Berikut ini adalah visualisasi bagan dari desain Kemmis dan Mc Taggart :

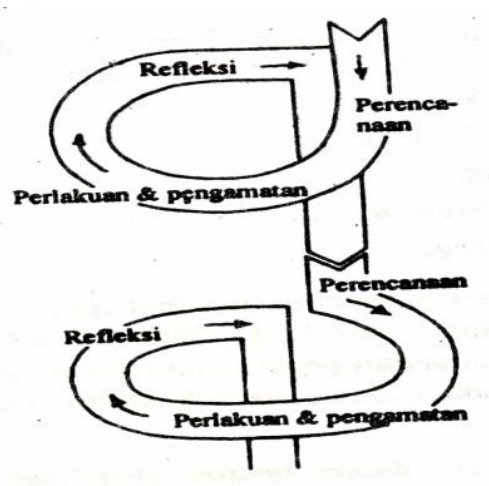

Gambar 2. Model Penelitian Kemmis dan Mc Taggart

Sumber : Suharsimi Arikunto. Prosedur Penelitian Tindakan, Suatu 
Pendekatan Praktik, Jakarta : Rineka Cipta, 2011

Dalam menganalisis hasil belajar gerak dribble bola basket dipergunakan lembar pengamatan psikomotor yang diperoleh dari skor total siswa dalam melakukan tes unsur-unsur gerak yang dinilai berdasarkan kebenaran dalam pelaksanaan tiap-tiap gerakan dan juga lembar kegiatan pelaksanaan selama penelitian. Berikut adalah fortofolio penilaian kemampuan gerak dribble bola basket.

\section{HASIL DAN PEMBAHASAN}

Berdasarkan hasil yang didapat dari tahap tindakan dan observasi pada siklus I didapat data bahwasannya dari 36 siswa terdapat 21 siswa $(58,33 \%)$ yang sudah mendapat nilai ketuntasan dalam belajar, sedangkan 15 siswa $(41,67 \%)$ belum mencapai tingkat ketuntasan belajar. Nilai Persentase ketuntasan klasikal (KKM) ratarata kelas yang diperoleh hanya mencapai 72. Dalam peneletian tindakan ini sebagai pelaku utama dan sekaligus juga kolabolator, sedangkan guru sebagai mitra peneliti yang akan melaksanakan rancangan pembelajaran di dalam kelas dan akan dibantu oleh teman sejawat sebagai observer mengamati pelaksanaan yang ada dilapangan. Perencanaan tindakan berdasarkan permasalah yang ada, pemilihan kemungkinan pemecahan masalahnya, implementasinya di lapangan sampai pada tahap evaluasi dan perumusan pada tindakan berikutnya. Proses penelitian tindakan ini dilaksanakan dalam rangka siklus, dan setiap siklus akan dilaksanakan dengan perubahan yang ingin dicapai. Berdasarkan data tersebut diperoleh hasil peneltian bahwa pada siklus I belum memenuhi kriteria keberhasilan proses pembelajaran passing bola basket pada siswa/siswi SMK BM SINAR HUSNI Helvetia.

Untuk itu, maka peneliti memutuskan untuk melanjutkan tindakan yang dapat meningkatkan pemahaman tentang proses pembelajaran passing (mengoper) bola melalui pendekatan bermain pada siklus II. Berdasarkan hasil observasi dan evaluasi bersama dengan guru bidang studi pendidikan jasmani dan melihat pada hasil belajar dari siklus I maka permasalahan yang ditemui adalah :

1. Masih banyak siswa yang belum memahami tahapan proses dalam passing bola basket yang benar, hasil tersebut diperoleh dari jumlah nilai sikap kepala pada sub indikator 1 saat menggiring bola yang berjumlah 230 dengan rata-rata 6,39

2. Masih banyak siswa yang belum bisa melakukan passing bola basket dengan benar, hasil tersebut dapat dilihat dari jumlah nilai sikap kepala pada sub indikator 2 saat mengoper bola yang menunjukan angka terendah dengan jumlah 210 dengan rata-rata 5,83

3. Masih banyak siswa yang belum bisa mengoper bola basket, hasil tersbut dapat diperoleh dari pengamatan sub 
indikator ke 3 pada sikap lengan dan tubuh saat mengoper bola basket yang belum berjumlah 185 dengan rata-rata 5,13.

Setelah dilakukan tindakan pada siklus II telah diperoleh peningkatan kemampuan hasil belajar passing bola basket jika dibandigakan dengan tes awal dan tes siklus I. Dalam siklus II ini proses belajar mengajar berjalan lebih baik jika dibandingkan dengan siklus I. Jika pada siklus I ketuntasan klasikal siswa siswa secara keseluruhan hanya 58,33\%, kemudian meningkat pada siklus II menjadi $88,89 \%$.

Dari data hasil belajar siklus II yang di dapat terlihat bahwa kemampuan siswa dalam melakukan tes hasil belajar klasikal sudah meningkat. Dari 36 siswa terdapat 32 orang siswa (89.89\%) yang telah mencapai ketuntasan belajar, sedangkan 4 siswa $(11,11 \%)$ yang belum mencapai ketuntasan belajar. Dalam siklus II ini proses belajar mengajar berjalan lebih baik jika dibandingkan dengan siklus I. Hasil belajar pada siklus II dapat meningkat karena pada siklus II para siswa menjadi lebih termotivasi dalam pembelajaran passing bola basket dengan pemberian berbagai variasi pembelajaran sehingga meningkatkan minat dan keaktivan seluruh siswa dalam mengikuti proses pembelajaran.

Berdasarkan hasil temuan refleksi, adapun ditemukannya permasalahan pada siklus II yaitu. (a) Terdapat 4 orang siswa yang belum tuntas dikarenakan belum dapat menguasai rangkaian gerakan passing bola basket dengan baik terutama pada aspek sikap lengan, dikarenakan siswa cenderung mendorong bola sebelum kedua lengan lurus yang seharusnya gerakan mengoper dilakukan setelah kedua lengan lurus. (b) Akibat dari hal tersebut di atas, siswa cenderung tidak dapat melakukan kegiatan sesuai ketentuan. Untuk membuat penelitian lebih sempurna lagi maka hal yang harus diperhatikan peneliti ialah hal yang telah teruraikan diatas. Dari data yang diperoleh baik secara KKM maupun klasikal siswa telah dikatakan tuntas, sehingga dapat di simpulkan bahwa melalui penerapan metode variasi pebelajaran dalam proses pembelajaran passing (mengoper) bola dapat meningkatkan hasil belajar passing (mengoper) bola siswa kelas $\mathrm{X}$ SMK BM SINAR HUSNI Helvetia.

Dari hasil penelitian yang dilakukan, terlihat bahwa pada siklus I masih banyak siswa yang belum mencapai ketuntasan belajar secara klasikal. Hal ini dikarenakan terdapat kesulitan-kesulitan yang dialami siswa selama pembelajaran, pada siklus II peneliti melakukan penambahan variasi pembelajaran sehingga pada siklus II pembelajaran dapat meningkat.

Dari analisis data awal diketahui bahwa hasil belajar siswa dari tes hasil belajar sebelum menggunakan metode variasi pembelajaran masih sangat rendah yaitu 
$30,56 \%$ dengan rata-rata ketuntasan

mimimal hanya 64. Kemudian telah terjadi

penigkatan hasil belajar pada siklus I setelah diberikan berbagai bentuk variasi, terlihat bahwa pada siklus I hasil persentase klasikal sebesar $58,33 \%$ dengan rata-rata ketuntasan minimal 72.22, kemudian meningkat menjadi $89,89 \%$ pada siklus II dengan rata-arta ketuntasan minimal sebesar 82,5. Hal ini berarti dengan memberikan berbagai macam variasi pembelajaran dapat meningkatkan hasil belajar passing bola basket siswa kelas $\mathrm{X}$ SMK BM Sinar Husni Helvetia.

\section{KESIMPULAN}

Berdasarkan hasil evaluasi belajar dribble bola basket siawa yang dilakukan pada tes awal, bahwasannya dari 36 siswa hanya terdapat 11 siswa atau sekitar $(30,56 \%)$ yang telah mencapai ketuntasan belajar, sedangkan 25 siswa lainnya atau sekitar $(69,44 \%)$ belum mencapai ketuntasan belajar. Dengan nilai rata-rata KKM siswa sebesar 63,91. sedangkan pada hasil belajar siklus I dapat dilihat kemampuan siswa dalam melakukan tes hasil belajar secara klasikal sudah meningkat, Yakni, dari 36 siswa terdapat 21 siswa atau sekitar $(58,33 \%)$ yang telah mencapai ketuntasan belajar sedangkan 15 siswa atau sekitar $(41,67 \%)$ belum mencapai ketuntasan belajar. Dengan nilai rata-rata hasil belajar secara klasikal sudah meningkat yakni mencapai 72.22. Sedangkan setelah diadakannya pembelajaran lanjutan pada siklus II, hasil belajar siswa menjadi lebih meningkat dari sebelumnya, yakni dari 36 siswa sudah terdapat 32 siswa atau sekitar $(89.89 \%)$ yang telah mencapai ketuntasan belajar sedangkan 4 orang siswa atau sekitar (11.11\%) belum mencapai ketuntasan belajar, dengan nilai rata-rata KKM sebesar 82,5. Berdasarkan hasil penelitian diatas maka dapat ditarik kesimpulan bahwa penerapan pembelajaran passing (mengoper) bola melalui metode variasi pembelajaran dapat meningkatkan hasil belajar passing (mengoper) bola pada permainan saling oper-oper bola bola basket siswa sekolah SMK BM Sinar Husni.

Berdasarkan temuan dan kesimpulan dari hasil penelitian dapat diketemukan beberapa implikasi sebagai berikut :

1. Penerapan metode variasi pembelajaran dalam proses pembelajaran dribble bola basket merupakan sebuah alternatif dalam memecahkan beberapa masalah yang dihadapi guru dalam upaya mengaktifkan siswa dalam belajar serta dalam upaya mentransformasikan nilainilai yang terkandung dalam pendidikan jasmani olahraga dan kesehatan, salah satunya adalah nilai disiplin, karena guru penjasorkes berperan sebagai pemimpin siswa, manajer yang mengelola kegiatan belajar dan mengajar.

2. Dalam setiap penerapan pembelajaran, seorang guru harus mampu menciptakan kelas yang konduksif agar hubungan interaktif siswa dengan guru, siswa dengan siswa dapat terwujud sehingga suasana kelas menjadi aktif dan menarik. Dalam hal ini guru harus mampu menjadi contoh dan teladan bagi siswanya, tidak hanya dalam kata-kata tetapi juga dalam perbuatan sehari-hari.

3. Dengan penerapan metode variasi pembelajaran dalam proses pembelajaran passing bola basket ini para siswa lebih tertantang, lebih termotivasi dan menjadi lebih aktif dalam proses pembelajaran, karena guru dan siswa sudah saling memahami berbagai aturan-aturan yang dibuat bersama sebelum pembelajaran dimulai. Oleh karenanya, dalam proses pembelajaran para siswa harus bersungguhsungguh dalam mengikuti pelajaran dan melakukan kegiatan pembelajaran, jika siswa tidak bersungguh-sungguh dalam pelaksanaan kegiatan maka para siswa akan mendapatkan sebuah hukuman.

Sebagai saran yang dapat diberikan peneliti sebagai berikut :

1. Disarankan pada Guru Pendidikan Jasmani SMK BM SINAR HUSNI Helvetia untuk dapat menggunakan pendekatan variasi pembelajaran pada 
proses pembelajaran pendidikan jasmani dalam upaya memperbaiki proses pembelajaran passing (mengoper) bola pada permainan bola basket.

2. Guru harus dapat lebih memahami pembelajaran dan seluruh rangkaian proses pembelajaran sehingga saat menerapkannya kepada para siswa sesuai dengan apa yang kita harapkan.

3. Hasil penelitian ini dapat dijadikan sebagai bahan rujukan bagi peneliti yang ingin mengangkat judul penelitian ini dalam rangka mengembangkan proses pembelajaran pendidikan jasmani khususnya pada passing bola basket.

4. Kepada para teman-teman mahasiswa Pasca Sarjana UNJ agar dapat mencoba melakukan Penelitian Action Research (AR) dengan menggunakan metode variasi pembelajaran yang lainnya dalam upaya meningkatkan hasil proses pembelajaran passing bola basket.

\section{DAFTAR PUSTAKA}

Arikunto, Suharsimi. Prosedur Penelitian, Suatu Pendekatan Praktek, (Jakarta : Rineka Cipta, 2011)

Aunurahman. Belajar dan Pembelajaran, (Bandung : Alfabeta, 2012)

Dimyati dan Mudjiono. Belajar dan Pembelajaran. (Jakarta: PT Rineka Cipta, 2009)

JS. Husdarta, Yudha M. Saputra. Belajar Dan Pembelajaran Pendidikan Jasmani dan Kesehatan,(Bandung : Alfabeta, 2013)

Nazir, Mochamad. Metode Penelitian. (Bogor: Ghalia Indonesia, 2005)

"Pedoman Penulisan Tesis dan Disertasi", Jakarta: PPS UNJ, 2012

Prusak, A. Keven. Permainan Bola Basket-50 Kegiatan Membangun Keterampilan Bola Basket. (Yogyakarta : Citra Aji Pratama, 2007)

Rahayu Ega Trisna. Strategi Pembelajaran Pendidikan Jasmani Implementasi Pada Pembelajaran pendidikan Jasmani, Olahraga dan Kesehatan, (Bandung : Alfabeta, 2013)

Sabri, Ahmad. Strategi Belajar Mengajar dan Micro Teaching. (Ciputat : Quantum Teaching, 2010)
Sudarta. J. S. Manajemen Pendidikan Jasmani. (Bandung: Alfabeta, 2009)

Syaiful Bahri Djamarah dan Azwan Zain, Strategi Belajar Mengajar, (Jakarta : Rineka Cipta, 2006)

M Aprial, Benny Dicky Hendrawan (2019) Modification of Athlete Equipment for Basic Level Physical Education Learning. In: Advances in Health Sciences Research, volume 23 1st Unimed International Conference on Sport Science (UnICoSS 2019)

Herry Koesyanto. 2016. Belajar Bermain Bola Volley. Semarang: FIK UNNES. 